\title{
Strut and tie model optimization for reinforced concrete deep beam using genetic algorithm
}

\author{
Bambang Piscesa ${ }^{a^{*}}$, Tavio Tavio ${ }^{\mathrm{a}}$
}

\begin{abstract}
This paper presents strut and tie model structural optimization of reinforced concrete deep beam using genetic algorithm. Genetic algorithm is used as the optimization platform as it does not require differentiation of the exact mathematical formulation to get the optimum solution. The force analysis is carried out using two-dimensional linear finite element method with truss element. The struts and ties design are based on ACI 318. One RC deep beam example is presented as an example. During optimization, there are two constraints which consisted of strength of the member alone and combination with deformation limit of the nodes. The stress ratio for both struts and ties are set to not exceed unity while the deformation was limited to $2.0 \mathrm{~mm}$. From the optimization analysis, it can be concluded that genetic algorithm can be used to get the most optimum structural configuration which yield the most economical solution for design purposes. On the other hand, it is found out that optimizing only the strength alone can yield a more economical solution compared to the design references. However, if deformation constraint is added in the optimization parameters, larger deep beam depth is required to satisfy the deformation limits.
\end{abstract}

Keywords: Structural optimization, strut and tie model, genetic algorithm, reinforced concrete

\section{INTRODUCTION}

The use of strut and tie model (STM) to design reinforced concrete element which governed by shear failure due to the presence of disturbed region is now being widely used as a more valid design method than the conventional reinforced concrete design. However, the STM modeling sequence requires a valid structural model that should be manually chosen based on established examples of known geometry and problems. For unexperienced designer, this modeling sequence may pose some difficulties. Limited guidelines on choosing the appropriate truss analogy system are also one of the main concerns.

For design purposes, some researchers provide guidance for the minimum angle of the truss system to provide the optimum design parameters for the STM. Schlaich and Weischede [1] suggested that the angle for STM element should have an angle larger than fifteen degree towards the main principal stress. The ACI 318-05 [2] noted that the angle between members that enters a node should not be less than twenty-five degrees. Rogowsky et. al [3] and Ramirez and Breen [4] suggested that the angle between members should be between twentyfive to sixty-five degrees. Grob and Thürlimann [5] also suggested that the angle between members should be between 26.6 to 63.4 degrees. Most of the references in the above consider the angle measurement based on many experimental studies.

In 2003, Zhu and coworkers [6] proposed a crack width prediction using compatibility strut and tie model. [6] raises the importance to check the deformability of shear dominated RC members which was caused by localized cracks. Hence, not only the shape of the STM that matters in design but also the deformability of the RC members should be also considered. To obtain the correct topological strut and tie model shapes, many researchers have used evolutionary optimization technique for various RC structures [7-12]. Liang et. al [13] use evolutionary optimization technique for RC deep beam with and without opening, and beam-column joint which was successful to get the best topology shape to be used in the STM analysis. In 2002, Liang et. al [14] extend their work to get the best topology shape of STM for a pier head structure which often used in bridges. However, this method only considers the elastic behavior of concrete elements which may cracks at lower tensile loads. Hence, the proposed method is only good to get the best topology of the STM.

To combine between optimizing the topology of STM model, the design of strength member, and to cater for the deformation of the structure, the author has develops an in house computer program which incorporates STM analysis and design based on truss finite element analysis and genetic algorithm optimization to get the best known topological shape of the STM model [15]. In this paper, only RC deep beam being investigated using the developed inhouse software. There are two objective function being considered in the GA optimization. The first objective only considers the strength of the member and the second objective includes the nodal vertical deformation checks which should be less than the deformation limit allowed.

\section{RESEARCH SIGNIFICANCE}

This paper presents optimization for strut and tie model in reinforced concrete deep beam using genetic algorithm. The GA optimization used in this paper is classified as topological optimization. An inhouse computer program is developed to support this research. There are two kind of objective function being investigated. The first objective function is optimization based on strength of the member alone and the second objective function is optimization based on strength combined with limited deformation. The additional limited deformation in the objective function is to cater for the need to check the deformation limit during the design.

\section{METHODOLOGY}

The methodology in this paper is divided into three steps. In the first step, a code-based design of reinforced concrete deep beam using STM is checked. The reinforced concrete deep beam being evaluated is taken from Singh et. al [16]. The RC deep beam have continuous span without interior span. Hence, there are three point of supports for the deep beam and two loading points positioned at the mid-span for each exterior span. Load control is considered in the analysis. The load for each loading points are not equal to 


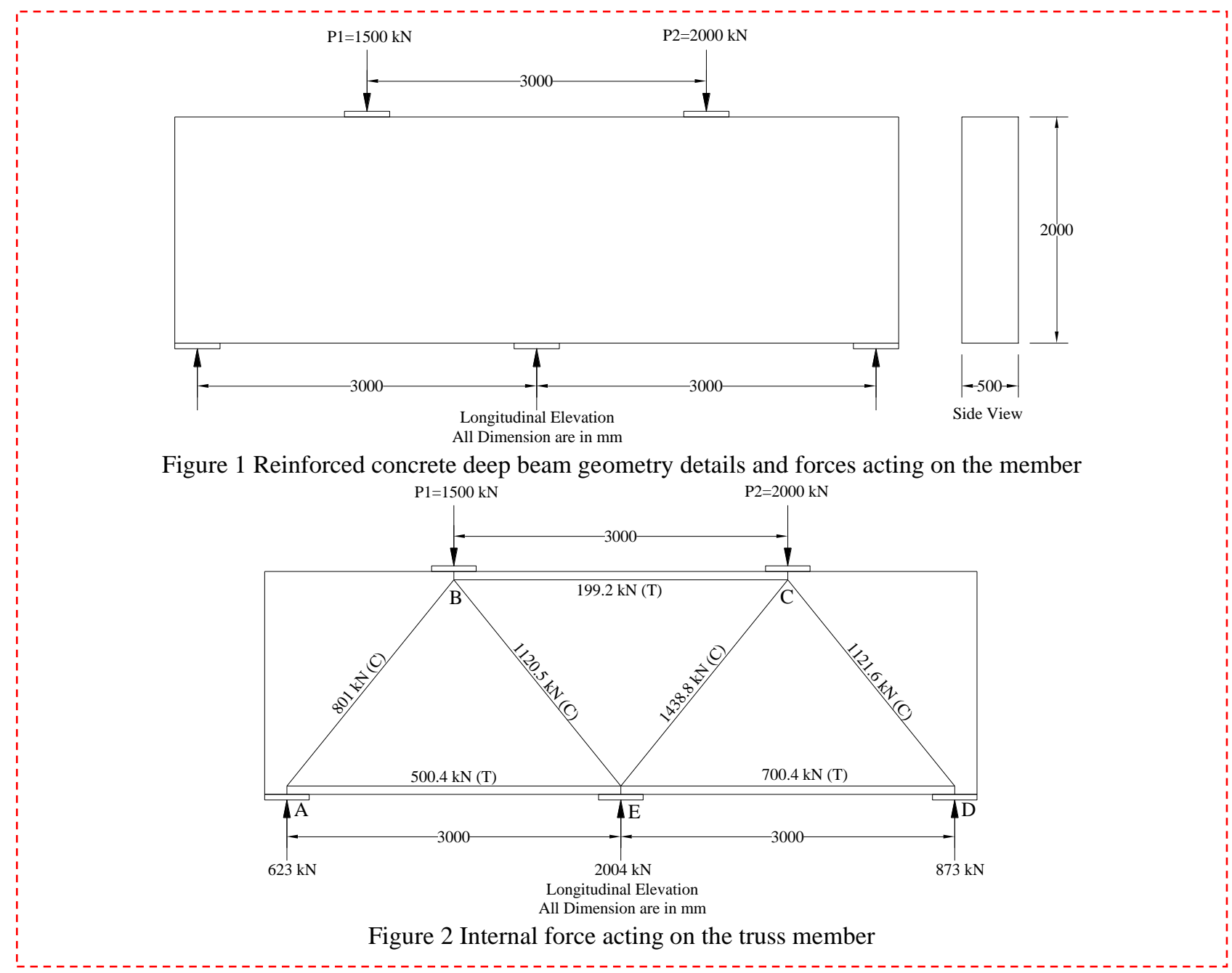

demonstrate the asymmetric loading pattern. The design of the members is based on ACI 318-05 [2].

In the second step, optimization of the RC deep beam is carried out with the objective function to optimize the topology of the truss element by using the member strength alone. In this step, for each populated gene in GA iterations are checked for the stress ratio for its member where it should be lower than unity. The topological optimization is constrained only in the vertical direction to ensure the beam have the same height through out the span. In addition, the loading points and support positions remains in its location. Hence, it is not necessary to do topological optimization in the horizontal direction.

In the third step, optimization of the RC deep beam is carried out with the objective function to optimize the topology of the truss element by using the member strength combined with limited deformation. The similar justification as in the second step is used except with the additional limited deformation to be checked in the analysis. The purpose to add this limited deformation in the GA optimization is to accommodate the needs to check the deformation of the member during the analysis.

\section{ANALYSIS AND DISCUSSIONS}

\section{A. ANALYSIS AND DESIGN OF THE REINFORCED CONCRETE DEEP BEAM USING STRUT AND TIE MODEL}

Figure 1 shows the geometry details of the RC deep beam and forces that acts on the member. The total span length of the beam is $6.0 \mathrm{~m}$ with each exterior span width is 3.0 $\mathrm{m}$. The beam width and height are $500 \mathrm{~mm}$ and $2000 \mathrm{~mm}$, respectively. The load applied at the left and right loading plates are $1500 \mathrm{kN}$ and $2000 \mathrm{kN}$, respectively. The distance between the loading plates measured from each centerline is $3.0 \mathrm{~m}$. Figure 2 shows the internal forces acting on the truss member and reaction at the support.

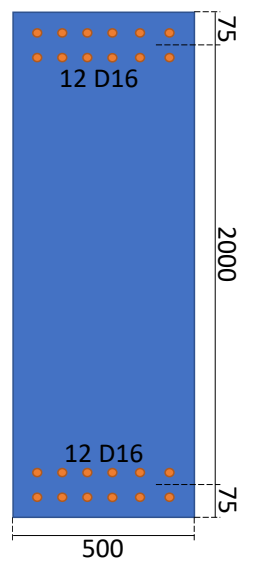

Figure $3 \mathrm{RC}$ deep beam design results

To determine the ties width, for each member with tensile forces, it is necessary to firstly compute the required bar area. Here, the bar yield strength was set to $414 \mathrm{MPa}$ and the uniaxial concrete compressive strength was set to 24 MPa. 


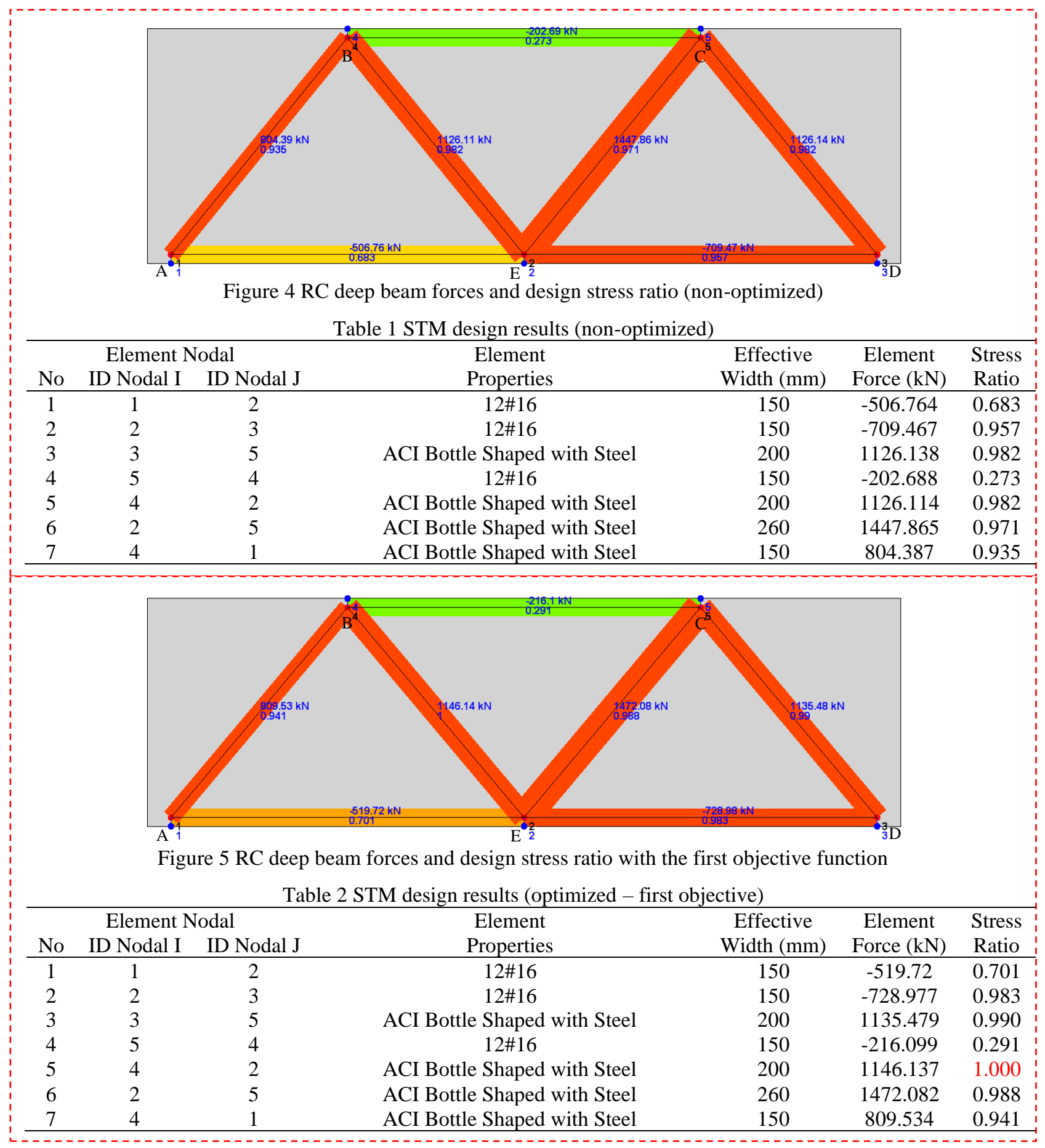

For member $\mathrm{AB}$, the required area can be computed as $199.2 * 1000 /(0.75 * 414)=640 \mathrm{~mm}^{2}$. For member AE, the required area is $500.4 * 1000 /(0.75 * 414)=1607 \mathrm{~mm}^{2}$. For member ED, the required area is $700.4 * 1000 /(0.75 * 414)=$ $2250 \mathrm{~mm}^{2}$. It should be noted that the reduction factor for tension is taken as 0.75 . A bar with $16 \mathrm{~mm}$ diameter $\left(\mathrm{A}_{\mathrm{sbar}}\right.$ $=201 \mathrm{~mm}^{2}$ ) is used for design. Hence, for member BC, AE, and $\mathrm{AD}$, the minimum required reinforcements are four, nine, and twelve bars, respectively. However, to ensure the bar continuity from point $\mathrm{A}$ to $\mathrm{D}$, the reinforcement for beam $\mathrm{AE}$ is adjusted from nine to twelve bars. The minimum reinforcement for ties element is $0.04 *\left(\mathrm{f}_{\mathrm{c}} / \mathrm{f}_{\mathrm{y}}\right) * \mathrm{~b} * \mathrm{~d}=0.04 *(24 / 414) * 500 * 1925=2226.5$ $\mathrm{mm}^{2}$. Hence, for beam $\mathrm{BC}$, the bar reinforcement also increased from four to twelve.
For compressive member, the capacity of compressive strut $\left(\phi \mathrm{f}_{\mathrm{cu}}\right)$ can be computed as $0.85 * \beta_{\mathrm{s}} * \mathrm{f}_{\mathrm{c}}=$ $0.75 * 0.85 * 0.75 * 24=11.47 \mathrm{MPa}$. Hence, the width for member $\mathrm{AB}=801.1 * 1000 /(11.47 * 500)=139.68 \mathrm{~mm}$. For member $\mathrm{BE}=1120.5 * 1000 /(11.47 * 500)=195.37 \mathrm{~mm}$. For member $\mathrm{CB}=1438.8 * 1000 /(11.47 * 500)=250.88 \mathrm{~mm}$. For member $C D=1121.6 * 1000 / 11.47 * 500=195.57 \mathrm{~mm}$. From minimum required member width, the design width for member $\mathrm{AB}, \mathrm{BE}, \mathrm{CB}$, and $\mathrm{CD}$, are $150 \mathrm{~mm}, 200 \mathrm{~mm}$, $260 \mathrm{~mm}, 200 \mathrm{~mm}$, respectively.

For the nodal zone, where node A, B, C, and D can be considered as CCT node. Therefore, the nodal strength based $\left(\phi \mathrm{f}_{\mathrm{cu}}\right)$ on ACI 318-05 [2] can be computed as $0.85 * \beta_{\mathrm{s}} * \mathrm{f}_{\mathrm{c}}=0.75 * 0.85 * 0.80 * 24=12.24 \mathrm{MPa}$. The minimum strut width to be extended to node $\mathrm{A}$ can be computed based on the width member AD and AB. From 


\begin{tabular}{|c|c|c|c|c|c|c|}
\hline \multicolumn{7}{|c|}{$\begin{array}{r}\text { Figure } 6 \text { RC deep beam forces and design stress ratio with the second objec } \\
\text { Table } 3 \text { STM design results (optimized - second objective) }\end{array}$} \\
\hline \multicolumn{4}{|c|}{ Element Nodal } & \multirow{2}{*}{\multicolumn{2}{|c|}{$\begin{array}{c}\text { Element } \\
\text { Properties }\end{array}$}} & \multirow{2}{*}{$\begin{array}{c}\text { Effective } \\
\text { Width (mm) }\end{array}$} \\
\hline No & \multirow{2}{*}{\multicolumn{3}{|c|}{ ID Nodal I }} & & & \\
\hline 1 & & \multicolumn{2}{|c|}{2} & \multicolumn{2}{|c|}{$12 \# 16$} & \\
\hline 2 & 2 & & & \multicolumn{2}{|c|}{$12 \# 16$} & \\
\hline 3 & \multicolumn{3}{|c|}{5} & \multicolumn{2}{|c|}{ ACI Bottle Shaped with Steel } & \\
\hline 4 & 5 & \multicolumn{2}{|c|}{4} & \multicolumn{2}{|c|}{$12 \# 16$} & \\
\hline 5 & 4 & \multicolumn{2}{|c|}{2} & \multicolumn{2}{|c|}{ ACI Bottle Shaped with Steel } & \\
\hline 6 & 2 & \multicolumn{2}{|c|}{5} & \multicolumn{2}{|c|}{ ACI Bottle Shaped with Steel } & \\
\hline 7 & 4 & & & \multicolumn{2}{|c|}{ ACI Bottle Shaped with Steel } & \\
\hline & \multicolumn{6}{|c|}{ Table 4 Nodal deformation for all STM models } \\
\hline & \multirow{3}{*}{$\begin{array}{c}\text { Nodal } \\
\text { ID }\end{array}$} & \multicolumn{5}{|c|}{ Nodal deformation in $\mathrm{x}$ and $\mathrm{y}$ direction in $\mathrm{mm}$} \\
\hline & & \multicolumn{2}{|c|}{ Code-based design } & \multicolumn{2}{|c|}{ Optimized $2^{\text {nd }}$ objective function } & Optimized $1^{\text {st }}$ objective function \\
\hline & & $\mathrm{x}$ & $\mathrm{y}$ & $\mathrm{x}$ & $\mathrm{y}$ & $\mathrm{x}$ \\
\hline & 1 & 0.000 & 0.000 & 0.000 & 0.000 & 0.000 \\
\hline & 2 & 0.946 & 0.000 & 0.795 & 0.000 & 0.984 \\
\hline & 3 & 2.726 & 0.000 & 2.273 & 0.000 & 2.840 \\
\hline & 4 & 0.866 & 1.847 & 0.749 & 1.730 & 0.894 \\
\hline & 5 & 1.497 & 2.212 & 1.231 & 1.996 & 1.565 \\
\hline
\end{tabular}

the calculation, the minimum required member width $\mathrm{AD}$ and $A B$ are $81.76 \mathrm{~mm}$ and $130.89 \mathrm{~mm}$, respectively. The reserved width for strut $\mathrm{AD}$ and $\mathrm{AB}$ were not less than 150 $\mathrm{mm}$ and thus it can be concluded that node $\mathrm{A}$ is adequate. The same calculation for node B, C, D, and E which also found to be have adequate strength.

Figure 3 shows the RC deep beam design results where the bottom and top longitudinal bars are consisted of twelve D16 bars. The bars are placed within two layers with the distance between the extreme outer concrete fiber to the bar centroid are $75 \mathrm{~mm}$. Hence, the width of ties is $150 \mathrm{~mm}$. Figure 4 shows the analysis and design results of the designed RC deep beam with the configuration as outlined in the previous section. Table 1 shows the element properties, effective width (as designed), element force, and stress ratio for each member. As shown in Figure 4 and Table 1, the maximum stress ratio was controlled by compression strut BE which is 0.982 .

\section{B. GA OPTIMIZATION OF THE RC DEEP BEAM STM USING THE FIRST OBJECTIVE FUNCTION}

In the first objective function, the code-based design STM is optimized by looking only at the member strength alone. Figure 5 shows the final forces and the stress ratio of the RC deep beam optimized using GA with the first objective function. As noted from Table 1, the maximum stress ratio for strut BE is 0.982 which still can be optimized if the stress limit can reach unity. From Figure 5, the stress ratio for member BE is 1.000 which then can be considered as the critical member design. From the GA optimization, the beam height was reduced to $1941 \mathrm{~mm}$. The final internal forces and stress ratio for all members optimized with the first objective function are shown in Table 2.

\section{GA OPTIMIZATION OF THE RC DEEP BEAM STM USING THE SECOND OBJECTIVE FUNCTION}

In the second objective function, the code-based design STM is optimized not only considering the member strength but also the deformation limits on node 5. Figure 6 shows the final forces and the stress ratio of the RC deep beam optimized using GA with the second objective function. Table 3 shows the details on the forces and stress ratio of the members. As shown in Figure 6 and Table 3, the previous critical member stress ratio (member $\mathrm{BE}$ ) from 0.982 to 0.914 . This clearly indicates that the previous deformed shape in node 5 was higher than the allowed limit which is $2.0 \mathrm{~mm}$. To satisfy the deformation limit, the optimized beam height increased from $2000 \mathrm{~mm}$ to 2271 $\mathrm{mm}$.

Table 4 shows the nodal deformation for all the generated STM models. As shown in Table 4, at node 5, for original STM designed using ACI 318-05 [2] code had a deformed value of $2.212 \mathrm{~mm}$ in the vertical direction. Hence, when it was optimized using strength alone as the 
objective function, GA will ignore the deformation limits. With a reduced beam height due to the optimization, the vertical deformation in node 5 increases from $2.212 \mathrm{~mm}$ to $2.276 \mathrm{~mm}$. However, as the deformation limits was added into the objective function, the vertical deformation in node 5 reduced from $2.212 \mathrm{~mm}$ to $1.996 \mathrm{~mm}$ which was close but still lower than the allowed limits $(2.0 \mathrm{~mm})$.

\section{FINAL DESIGN RESULTS BASED ON THE FIRST AND SECOND OBJECTIVE FUNCTION}

From the analysis in the previous sections, it can be inferred that there are three design results. The first one is the code-based design results which was shown in Figure 3. The second and the third results are the GA optimized STM results using the $1^{\text {st }}$ and the $2^{\text {nd }}$ objective function. Figure 7 shows the final design of the optimized RC deep beam geometry. In Figure 7, the optimum RC deep beam height with the $1^{\text {st }}$ and the $2^{\text {nd }}$ objective function are 1941 $\mathrm{mm}$ and $2271 \mathrm{~mm}$, respectively. It should be noted that here the reinforcing bar design was not changed during optimization.

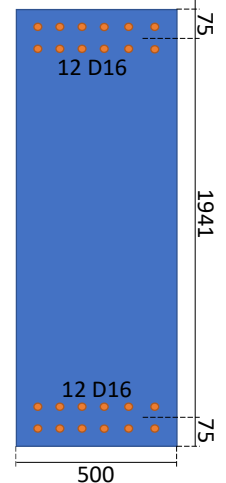

(a)

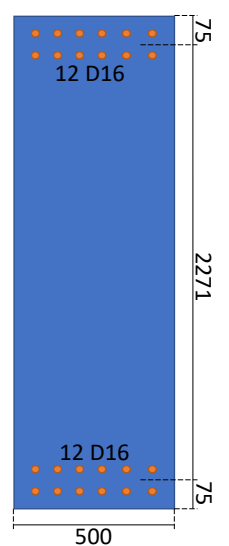

(b)
Figure 7 RC deep beam result based (a) First objective function (b) second objective function

\section{CONCLUSIONS}

This paper has presented a genetic algorithm-based optimization for strut and tie model of a continuous reinforced concrete deep beam. A standard genetic algorithm was used. There are two objective function being investigated. The first objective function tried to optimize the STM by focusing on the member strength alone while the second objective function includes the consideration of deformation limits in the analysis. This way, not only the strength but also the serviceability limit states are being evaluated at the same time.

From the analysis, it was found out that for the $1^{\text {st }}$ objective function applied in GA, the RC deep beam height can be reduced and maximizes the stress-ratio utilization up to unity. This way, the most economical design solution was achieved. On the other hand, where the $2^{\text {nd }}$ objective function was applied in GA, the RC deep beam height was increased. This can be understood as the vertical deformation of the code-based design was more than the limits. Hence, more inertia from the beam heigh was required. For that reason, the results from GA gives a solution where both the member strength and vertical deformation of the $\mathrm{RC}$ deep beam were satisfied by increasing the beam height.
In the future work, more complex optimization parameters which includes the number of bars, check on the nodal zone capacity, width of both the struts and ties, and also topology of the truss element should be investigated for more flexibility option in the optimization. This way, the most economical but safe RC member can be designed with sufficiently fast and efficient.

\section{REFERENCES}

[1] J. Schlaich and D. Weischede, "Detailing of concrete structures," Bulletin d'Information, vol. 150, p. 163, 1982.

[2] A. Committee, "Building code requirements for structural concrete (ACI 318-05) and commentary (ACI 318R-05)," 2005: American Concrete Institute.

[3] D. M. Rogowsky, J. G. MacGregor, and S. Y. Ong, "Tests of reinforced concrete deep beams," 1983.

[4] J. A. Ramirez and J. E. Breen, "Evaluation of a modified truss-model approach for beams in shear," Structural Journal, vol. 88, no. 5, pp. 562-572, 1991.

[5] J. Grob and B. Thürlimann, "Ultimate strength and design of reinforced concrete beams under bending and shear," in Ultimate Strength and Design of Reinforced Concrete Beams under Bending and Shear/Résistance et dimensionnement des poutres en béton armé soumises à la flexion et à l'effort tranchant/Bruchwiderstand und Bemessung von Stahlbetonbalken unter Biegung und Schub: Springer, 1976, pp. 107-120.

[6] R. R. Zhu, W. Wanichakorn, T. T. Hsu, and J. Vogel, "Crack width prediction using compatibility-aided strut-and-tie model," Structural Journal, vol. 100, no. 4, pp. 413-421, 2003.

[7] R. Perera and J. Vique, "Strut-and-tie modelling of reinforced concrete beams using genetic algorithms optimization," Construction and Building Materials, vol. 23, no. 8, pp. 2914-2925, 2009.

[8] R. Perera, J. Vique, A. Arteaga, and A. De Diego, "Shear capacity of reinforced concrete members strengthened in shear with FRP by using strut-and-tie models and genetic algorithms," Composites Part B: Engineering, vol. 40, no. 8, pp. 714-726, 2009.

[9] X. Liu, W.-j. Yi, and P.-s. Shen, "Topology optimization of strut-and-tie models in deep reinforced concrete beams," Engineering Mechanics, vol. 9, 2006.

[10]F. Bontempi and P. G. Malerba, "Stress path adapting strut-and-tie models in cracked and uncracked RC elements," Structural Engineering and Mechanics, vol. 12, no. 6, pp. 685-698, 2001.

[11] A. N. Hanoon, M. Jaafar, F. Hejazi, and F. N. A. Aziz, "Strut-and-tie model for externally bonded CFRPstrengthened reinforced concrete deep beams based on particle swarm optimization algorithm: CFRP debonding and rupture," Construction and Building Materials, vol. 147, pp. 428-447, 2017.

[12] J. L. Jewett and J. V. Carstensen, "Experimental investigation of strut-and-tie layouts in deep RC beams designed with hybrid bi-linear topology optimization," Engineering Structures, vol. 197, p. 109322, 2019. 
[13] Q. Q. Liang, Y. M. Xie, and G. P. Steven, "Topology optimization of strut-and-tie models in reinforced concrete structures using an evolutionary procedure," American Concrete Institute, 2000.

[14] Q. Q. Liang, B. Uy, and G. P. Steven, "Performancebased optimization for strut-tie modeling of structural concrete," Journal of Structural Engineering, vol. 128, no. 6, pp. 815-823, 2002.

[15]B. Piscesa, "Optimasi sudut dan deformasi strut-andtie model dalam perancangan elemen struktur beton bertulang," Master Theses, Civil Engineering Department, Institut Teknologi Sepuluh Nopember, 2008.

[16]B. Singh, S. Kaushik, K. Naveen, and S. Sharma, "Design Of A Continuous Deep Beam Using The Strut and Tie Method," 2006. 